\title{
Indications of Primary Cesarean Section In Multipara
}

\author{
Shazia Aftab, Nazish Ali, Fehmida Saleh, Saira Ghafoor, Aasha Mahesh, Sheena Memon
}

ABSTRACT

Objective: To evaluate the indications of primary cesarean section in multipara and to assess the obstetric outcome including maternal, fetal morbidity and mortality, perinatal outcome.

Study Design and Setting: It was a hospital based study of primary caesarean sections (CS) done on multiparous patients in duration of two years between January 1, 2016, and December 2017 at Jinnah medical college hospital Karachi.

Methodology: Multiparous patients were those who had delivered through vaginal route one or more times (i.e. 28 weeks of gestation or above) or had 1-4children and grand-multiparous are those who had 5 or more children. All the cases included in the study were hospital based and cesarean section was decided by specialist. The procedure was performed by registrars and specialists. The selected patients were followed up till they were discharge from the ward with minimum hospital stay of three days. Data was compiled and results were carried out by SPSS version 23.

Results: During the two years of study period, the number of total deliveries were 2064. The primary CS rate in multipara was $37.17 \%$. These women have more likely to have an emergency cessarean sections compared to elective i.e. $85 \%$ and $15 \%$. The mean age of women was 29.5 years, booked cases were $72.5 \%$ and unbooked were $27.5 \%$. Regarding indications for cesarean sections, non-progress of labour ranked first $25.5 \%$ followed by fetal distress $20 \%$, pre eclampsia $12 \%$ and ante partum hemorrhage $10.5 \%$ etc. Increase incidence of morbidity and mortality was seen in patients undergoing cesarean section due to different reasons.

Conclusion: Primary caesarean sections in multipara comprise only a small percentage (37.17\%) of total deliveries but were related to high maternal and fetal morbidity.

Keywords: cessarean section rate, indications of cessarean section, multiparous.

\section{INTRODUCTION:}

Cesarean section is the most commonly performed surgical procedures; in many cases it can be life-saving for the mother, fetus or both ${ }^{1}$. Cesarean section is generally performed these days, when a vaginal delivery would lay the baby's or mother's life or health at risk. ${ }^{2}$

Shazia Aftab
Associate Professor Department of OBS/GYNAE
Jinnah Medical College Hospital Karachi
I Email: drshaziaaftab@gmail.com
Nazish Ali
I Senior Registrar, Department of OBS/GYNAE
I Jinnah Medical College Hospital Karachi
I Fehmida Saleh
I Senior Registrar, Department of OBS/GYNAE
I Jinnah Medical College Hospital Karachi
I Saira Ghafoor
I Assistant Professor, Department of OBS/GYNAE
I Jinnah Medical College Hospital Karachi
| I
Iasha Mahesh
I Professor, Department of OBS/GYNAE
Innah Medical College Hospital Karachi
I Sheena Memon
I Associate Professor, Department of OBS/GYNAE
I Jinnah Medical College Hospital Karachi
I Received: 31-10-18
I Accepted: 07-03-19

In the past years there has been a significant rise in the rate of caesarean section (CS) in both developed and developing countries rising from about $5 \%$ in developed countries to more than $50 \%$ in some regions of the world. ${ }^{3}$

According to World Health Organization (WHO) study during the period of 2007-8 the rates of caesarean section in China and other Asian countries were $46 \%$ and $27 \%$, respectively in spite of $10-15 \%$ suggested by WHO. ${ }^{10}$

With the passage of time there has been a change in the indications for caesarean section and the rate of both primary and repeat caesarean delivery have been on the rise, A study by Emma L Barber et al concluded that primary caesarean births accounted for $50 \%$ of the increase in caesarean section rate. $^{5}$

It is essential to evaluate the several indications, maternal and fetal outcome related with a cesarean delivery as several studies have established that cesarean section causes a greater risk of maternal morbidity, and mortality in comparison to vaginal deliveries. $^{1}$

Primary caesarean section in multipara means first caesarean section done in the women who had delivered through vaginal route previously a viable fetus. Since these women (multiparous) have had previous uneventful labours, a sense of false security prevails in them and as a result such multiparous mothers often overlook there regular antenatal checkup and labour. There are still many doctors with an attitude of satisfaction that once a woman had passed through 
her first pregnancy and labour, she had practically nothing to worry about her subsequent childbirths. ${ }^{6}$ The rapid rise in the rate of cesarean section in the current years warrant serious concern. Pakistan being a developing country have shown an alarming increase in the rate of cesarean section deliveries Haidar $\mathrm{G}$ et al from Hyderabad and Shamshad from Abbotabad Pakistan reported caesarean section rate as high as $67.7 \%{ }^{7}$ and $45.1 \%$ in $2007 .{ }^{8}$ The rationale of the study was to assess the CS in Karachi.

\section{METHODOLOGY:}

It was a hospital based study of primary caesarean sections done on multiparous patients in duration of two years between January 1, 2016, and December 2017 at Jinnah medical college hospital which is a tertiary care hospital. Multiparous patients are those who had delivered through vaginal route one or more (i.e. 28 weeks of gestation or above) or had 1-4 children and grand-multiparous were those who had 5 or more children. All the cases included in the study were hospital based and cesarean section was decided by specialist. The procedure was performed by registrars and specialists. The selected patients were followed up till they were discharged from the ward with minimum hospital stay of three days. The patient's information was collected with the help of doctor present on the duty. The demographic data; included were age, parity, gravidity, maternal medical history; specific information on maternal or fetal pregnancyrelated complications; booked and unbooked status, mode of delivery, gestational age (measured according to the last menstrual period), (and it was confirmed by an ultrasound examination within 20 weeks of gestation or by the first trimester ultrasound measurement of the crown-rump length of the fetus), all primary indications for cesarean sections, the newborn's sex, birth weight and apgar score; and the maternal and perinatal outcomes and the need for ICU admission. All adverse maternal and fetal outcomes were recorded. All those females who were primigravida and previous cesarean section were excluded from the study. Informed consent was obtained from all participants. The study was approved by the hospital's research and ethics committee.

Statistical analysis was conducted using SPSS version 23. For continuous variables minimum, maximum, mean, and standard deviation were calculated. Chi-square test was used for categorical variables.

\section{RESULTS:}

During the two years total deliveries were 2064 out of which vaginal deliveries were 1278 i.e. $61.91 \%$ and total cessarean section were 786 with rate of 38.08 . The multiparous women were 200 in number in which primary cesarean section was done and cesarean section rate came out to be $37.17 \%$.

These women have more likely to have an emergency cessarean sections compared to elective i.e. $85 \%$ and $15 \%$. The overall incidence of primary emergency and elective caesarean section rate was shown in table no 1 . The mean age of women was 29.5 years with range from 15 to 45 years, the $66 \%$ of women presents between $26-35$ years of age and $72 \%$ presents between 31-40 years. Among 200 multiparous patients which undergoing cessarean section, $87.5 \%$ presents with parity $1,2,3$ and 4 while grand multiparity (5+ births) prevalent in $12.5 \%$ of all women. Prevalence of cesarean section according to parity was present in table no 2. Booked cases were 402 (72.5\%) and unbooked were $136(27.5 \%)$. The overall indications for cesarean sections were shown in table no. 3 , in which non progress of labour ranked first $(25.5 \%)$ followed by fetal distress $(20 \%)$ etc.

Increase incidence of morbidity and mortality was seen in patients undergoing cesarean section due to different reasons. The number of patients who had, blood transfusion were fifteen, patients with prolong hospital stay were six due to (wound infection, obstructed labour, blood pressure and sugar monitoring), two patients had obstetrical hysterectomy and forty three babies were admitted in NICU due to fetal distress, neonatal jaundice, hypoglycemia, growth restriction and neonatal sepsis.

\section{DISCUSSION:}

A woman who had normal vaginal delivery still may require a caesarean section for safe delivery. The average labor curve continues to change from low parity to multiparity but not toward an ever improved progress.

\begin{tabular}{|l|c|c|}
\hline & Frequency & Percent \\
\hline Total no. of Primary Cesarean sections & 538 & 26.06 \\
\hline Primary Cesarean section in multiparous & 200 & 37.17 \\
\hline Total emergency Cesarean section & 456 & 84.75 \\
\hline Total elective Cesarean section & 82 & 15.24 \\
\hline $\begin{array}{l}\text { Primary emergency Cesarean section in } \\
\text { multiparous }\end{array}$ & 170 & 85 \\
\hline $\begin{array}{l}\text { Primary elective Cesarean section in } \\
\text { multiparous }\end{array}$ & 30 & 15 \\
\hline
\end{tabular}

Table 1: Frequency of primary caesarean section

\begin{tabular}{|l|c|c|c|}
\hline Parity & $\begin{array}{c}\text { Age / no. } \\
\text { of pt }\end{array}$ & $\begin{array}{c}\text { Age / no. } \\
\text { of pt }\end{array}$ & $\begin{array}{c}\text { Total no. } \\
\text { of pt \%o }\end{array}$ \\
\hline Para 1 & $15-20(12)$ & $21-25(17)$ & $29(14.5 \%)$ \\
\hline Para 2 & $21-25(16)$ & $26-30(24)$ & $40(20 \%)$ \\
\hline Para 3 & $26-30(15)$ & $31-35(41)$ & $56(28 \%)$ \\
\hline Para 4 & $31-35(22)$ & $36-40(28)$ & $50(25 \%)$ \\
\hline Para 5 & $36-40(15)$ & - & $15(7.5 \%)$ \\
\hline Para 6 & $36-40(8)$ & $41-45(2)$ & $10(5 \%)$ \\
\hline
\end{tabular}

Table 2: Parity And Frequency Of Caesarean Section 
A Descriptive Analysis of Indications of Primary Cesarean Section In Multipara

\begin{tabular}{|c|c|c|c|c|c|c|c|c|c|}
\hline \multirow[b]{2}{*}{ Indication } & \multicolumn{6}{|c|}{ Parity } & \multirow[b]{2}{*}{ Total } & \multirow{2}{*}{$\begin{array}{l}\text { Total } \\
\text { multi }\end{array}$} & \multirow[b]{2}{*}{$\%$} \\
\hline & $\begin{array}{c}\text { Primig- } \\
\text { ravida }\end{array}$ & 2 & 3 & 4 & 5 & $\begin{array}{l}6 \text { and } \\
\text { more }\end{array}$ & & & \\
\hline Npol & 105 & 19 & 20 & 10 & 2 & 0 & 156 & 51 & $25 \%$ \\
\hline PE, Eclampsia & 10 & 5 & 4 & 9 & 4 & 2 & 34 & 24 & $12 \%$ \\
\hline Iugr & 19 & 2 & 3 & 4 & 0 & 0 & 28 & 9 & $4.5 \%$ \\
\hline Twin & 8 & 2 & 2 & 0 & 0 & 0 & 12 & 4 & $2 \%$ \\
\hline Chorioamnionitis & 4 & 0 & 1 & 0 & 0 & 2 & 7 & 3 & $1.5 \%$ \\
\hline Cpd & 15 & 1 & 1 & 2 & 3 & 1 & 15 & 8 & $4 \%$ \\
\hline Maternal Request & 25 & 4 & 1 & 0 & 0 & 0 & 25 & 5 & $2.5 \%$ \\
\hline Boh & 0 & 0 & 1 & 1 & 0 & 0 & 2 & 2 & $1 \%$ \\
\hline Post Term & 15 & 2 & 0 & 0 & 0 & 0 & 17 & 2 & $1 \%$ \\
\hline Fetal Distress & 70 & 18 & 15 & 5 & 1 & 1 & 116 & 40 & $20 \%$ \\
\hline GDM & 6 & 2 & 5 & 4 & 4 & 2 & 24 & 17 & $8.5 \%$ \\
\hline Failed Induction & 25 & 0 & 2 & 0 & 0 & 0 & 27 & 2 & $1 \%$ \\
\hline Breech & 23 & 4 & 3 & 1 & 0 & 0 & 31 & 8 & $4 \%$ \\
\hline Placentprevia & 5 & 2 & 4 & 1 & 2 & 1 & 15 & 10 & $5 \%$ \\
\hline Placenta Abruptio & 7 & 4 & 2 & 2 & 3 & 0 & 18 & 11 & $5.5 \%$ \\
\hline Obstructed Labor & 1 & 1 & 1 & 0 & 2 & 0 & 5 & 4 & $2 \%$ \\
\hline Total & 338 & 66 & 65 & 39 & 21 & 9 & 538 & 200 & \\
\hline
\end{tabular}

Table 3: Indication and Parity Crosstabulation

The primary caesarean sections in multipara comprise small proportion of total deliveries i.e $9.6 \%$ in our study which was relatively less than primary caesarean in primipara, but were actually associated with high maternal and fetal morbidity it is of concern.

In the study primary lscs in multipara constitutes $37.17 \%$, however it is still higher than the World Health Organization recommendation of $15 \%{ }^{10}$ but is in the range of cesarean sections performed in United States i.e $34 \%^{2}$ but low than a highest level of $46 \%$ in China ${ }^{4}$, and other parts of Pakistan $67.7 \%$ and $45.1 \%$ in $2007^{8}$. During labour it is now easier to determine the risks relating to the mother and the baby earlier due to increased use of technology, which can be somewhat related to increase in the amount of cesarean sections.

The rate of emergency caesarean section is much higher 85 $\%$ than the elective caesarean section i.e. $15 \%$ this is similar to earlier studies in Pakistan ${ }^{12,13,}$ Saxena $\mathrm{N}$ et al study ${ }^{11}$ and Nigeria ${ }^{14}$ etc and might be because of the prevalence of such factors as cephalo-pelvic disproportion and prolonged obstructed labour which are diagnosed in labour another probable explanation could be the great aversion to operative delivery in this environment which makes women 'surrender' to surgery as a last result .

The rate of emergency caesarean section is much higher 85 $\%$ than the elective caesarean section i.e. $15 \%$ this is similar

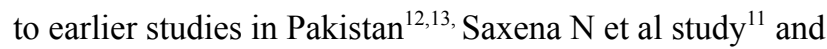
Nigeria ${ }^{14}$ etc which might be because of the prevalence of factors such as prolonged labour or cephalo-pelvic disproportion which are diagnosed in the labour are could be the possible explanation for emergency cesarean section instead of instrumental vaginal delivery.
In the present study maximum number of women undergoing primary caesarean section were in the age group of 3140 years i.e. $72 \%$ and $66 \%$ presents bw $25-35$ years which is also found in other researches i.e. Partha Saradhi et al study where as In Adnan A. Abu Omar series maximum number of patients were in the age group of $<25$ years $^{15}$.

Prolonged labor and fetal compromise remained the major indications for emergency cesareans. The commonest indications observed in this study were failure to progress $25.5 \%$, fetal distress $20 \%$, pre eclampsia $12 \%$, APH $10.5 \%$ etc which are similar to findings from other studies. A study conducted in the $\mathrm{US}^{16}$, in urban Bangladesh ${ }^{17}$ and by Boyle A, Reddy UM and Landy HJ, etc ${ }^{18}$ concluded the same indications for primary cesarean deliveries. In the majority of our patients i.e $72.5 \%$ were booked cases while $27.5 \%$ were unbooked which is comparable to $78.4 \%$ of Partha Saradhi et al study.

Increase incidence of morbidity and mortality is seen in patients undergoing cesarean section due to various reasons.

In the study postoperative complication rate was $11.5 \%$ which is nearer to $12 \%$ cases of Sethi Pruthwiraj et al study ${ }^{1}$, patients who had blood transfusion were $7.5 \%$, patients with prolong hospital stay were $3 \%$ due to (wound infection, obstructed labour, blood pressure and blood sugar monitoring ) and two patients had obstetrical hysterectomy due to postpartum hemorrhage. Regarding to neonatal morbidity $21.5 \%$ were admitted in NICU due to fetal distress, neonatal jaundice, hypoglycemia, intra uterine growth restriction and neonatal sepsis similar to results observed in other studies ${ }^{5,1}$. There was no maternal death observed in the study. This may be because of the skilled obstetrician attendant at birth, 
effective care during labour, management of pregnancy complications, availability of antibiotics, blood transfusion facilities and effective neonatal intensive care and early referral. The limitation of the study were the one public healthcare hospital in one territory. Further analysis in respective areas about indications and prevelance of primary caesarean section in the multiparous may be performed.

\section{CONCLUSION:}

Primary caesarean sections in multipara comprise only a small percentage of total deliveries but are related with high maternal and fetal morbidity. Due to previous normal deliveries these woman passes in a subnormal state of health throughout their pregnancy and labour, so they should be emphasized for good antenatal and intrapartum care and expert supervision periodically for any unforeseen emergencies.

\section{REFERENCES:}

1. Sethi P, Vijaylaxmi S,Shailaja G, Bodhare T, Devi S. A study of primary cesarean section in multigravidae. Perspectives in medical research $2014 ; 2: 3-7$.

2. Boruff, K.Health grades revealsc section rates across America. 2012. Available from: http://www.healthgrades.com/ratingsand-awards/national-maternity-care Downloaded 12.02.2013.

3. Villar J, Valladares E, Wojdyla D, Zavaleta N, Carroli G, Velazco A, Caesarean delivery rates and pregnancy outcomes: the 2005 WHO global survey on maternal and perinatal health in Latin America. Lancet 2006, 367:1819-1829.

4. Lumbiganon P, Laopaiboon M, Gulmezoglu AM, Souza JP, Taneepanichskul S, Ruyan P, World Health Organization Global Survey on Maternal and Perinatal Health Research Group: Method of delivery and pregnancy outcomes in Asia: the WHO global survey on maternal and perinatal health 2007-08. Lancet 2010, 375:490-499.

5. Monitta Moni et al A study on obstetric profile of mothers undergoing primary caesarean section and their neonatal outcome in a tertiary care centre, South Kerala. International Journal of Biomedical and Advance Research 2015; 6(12): 835-838.
6. Meha Agrawall, Supriya Waydande Frequency and indications of primary caesarean section hospital, Sangli, Maharashtra, INDIA. International Journal of Recent Trends in Science And Technology, 2016;18(3):430-432.

7. Haider G, Zehra N, Munir AA, Haider A. Frequency and indication of caesarean section in a tertiary care hospital. Pak J Med Sci: 2009; 25(5): 791-796.

8. Shamshad. Factors leading to increased caesarean section rate. Gomal J Med Sci: 2008: (1): 1-5.

9. Dr. J.K.Saluja, Dr P K Roy, Dr. K. Mahadik Assoc Prof, Prof. R.D. Study of Primary Caesarean Section In Multiparous Women, Gardi Medical College, Ujjain NJIRM 2014; 5(2):

10. Akinola et al. Caesarean section - an appraisal of some predictive factors in Lagos Nigeria BMC Pregnancy and Childbirth 2014, 14:217

11. Namrata Saxena, Bhawna Sharma, Vineeta Gupta, Kamal S. Negi. A six year appraisal of caesarean delivery at a teaching hospital in Uttarakhand . Int J Reprod Contracept Obstet Gynecol. 2016;5(12):4369-72.

12. KhawajaNP, Yousaf T, Tayyeb R: Analysis of caesarean delivery at a tertiary care hospital in Pakistan. J ObstetGynaec 2004, 24:139-141.

13. Najmi SR, Renan N: Prevalence and determinants of caesarean section in a teaching hospital in Pakistan. J Obstet Gynaecol 2000, 20(5):479-483.

14. OlusanyaBO, Solanke OA: Maternal and neonatal factors associated with mode of delivery under a universal newborn hearing screening programme in Lagos, Nigeria. BMC Pregnancy Childbirth 2009, 9:41.

15. Dr. G .Partha Saradhi Reddy, Dr.S.VenkataRamana, Dr. Salma Bhanu. Clinical Study of Primary Caesarean Section in Multiparous Women. Indian Journal Of Research 2015;4(10):

16. Tita AT: When is primary cesarean appropriate: maternal and obstetrical indications. SeminPerinatol 2012, 36:324-327.

17. SahaL, Chowdhury SB: Study on primary cesarean section. Mymensingh Med J 2011, 20:292-297.

18. Boyle A et al. Primary caesarean delivery in the United States. Obstet. Gynecol 2013;122:33-40. 